\title{
DESIGN OF ATOMIZERS AND BURNERS FOR COAL-WATER SLURRY COMBUSTION
}

\author{
QUARTERLY ACTIVITY REPORT \\ Period Starting: 1 July 1998 \\ Period Ending: 30 September 1998 \\ Rony Hitron, William Humphrey, and Norman Chigier
}

1 October 1998

DOE Award Number: DE-FG22-95PC95105--12

Spray Systems Technology Center

Carnegie Mellon University

5000 Forbes Avenue

Pittsburgh, PA 15213 


\section{Disclaimer}

This report was prepared as an account of work sponsored by an agency of the United States Government. Neither the United States Government nor any agency thereof, nor any of their employees, makes any warranty, express or implied, or assumes any legal liability or responsibility for the accuracy, completeness, or usefulness of any information, apparatus, product, or process disclosed, or represents that its use would not infringe privately owned rights. Reference herein to any specific commercial product, process, or service by trade name, trademark, manufacturer, or otherwise does not necessarily constitute or imply its endorsement, recommendation, or favoring by the United States Government or any agency thereof. The views and opinions of authors expressed herein do not necessarily state or reflect those of the United States Government or any agency thereof. 


\section{Abstract}

A detailed compressible airflow analysis was performed on the central air passage of the triple-concentric atomizer. The results show that a minimum mass flow rate of $0.33 \mathrm{~g} / \mathrm{s}$ $(\approx 16 \mathrm{~L} / \mathrm{min}$ at STP) of air at a supply pressure of $296 \mathrm{kPa}$ (absolute) is required to create a sonic flow at the atomizer exit, which is $0.97 \mathrm{~mm}$ in diameter. This result confirms the hypothesis that previous parametric visualization studies of the spray cone did not have sonic air flow in all cases. Additionally, Phase/Doppler droplet size and velocity measurements were made in sprays of both water and a dilute solution $(0.05 \% \mathrm{wt} / \mathrm{wt})$ of high-molecular weight polyacrylimide. The measurements show small increases in mean drop size when the polymer is added to the liquid, which are nevertheless large compared to the percentage of polymer solute in the solution. 


\section{Table of Contents}

$\begin{array}{ll}\text { Disclaimer } & 2\end{array}$

$\begin{array}{ll}\text { Abstract } & 3\end{array}$

Executive Summary

Introduction $\quad 5$

$\begin{array}{lc}\text { Results and Discussion } & 6\end{array}$

$\begin{array}{ll}\text { Conclusion } & 10\end{array}$

Projected Activity for Next Period $\quad 11$

References 11

\section{List of Figures}

Figure 1: Center Air Passages, Miniature Triple-Concentric Atomizer 12

Figure 2: Schematic Diagram, Triple-Concentric Atomizer 12

Figure 3: Drop Sizes, Water spray vs. Polymer solution spray 13 


\title{
DESIGN OF ATOMIZERS AND BURNERS FOR COAL- WATER SLURRY COMBUSTION

\author{
Grant Number: DE-FG22-95PC95105
} \\ Progress Report for Period 7/1/98 - 10/30/98
}

\author{
Dr. R. Hitron, Wm. Humphrey and Dr. N. Chigier \\ Spray Systems Technology Center \\ Dept. of Mechanical Engineering, Carnegie Mellon University \\ Pittsburgh, PA 15213
}

\section{Executive Summary}

Detailed compressible airflow analysis reveals that the minimum air supply conditions for sonic exit flow were not met in previous visualization experiments on the triple-concentric atomizer. Phase/Doppler measurements of droplet size and velocity in both water and polymer solution sprays show that the polymer solution spray has slightly larger mean drop sizes that the water spray. Even this slight effect is important, however, especially when considering that the polymer content was only $0.05 \%$ by weight.

\section{Introduction}

This report documents the activities and results from the period 1 July 1998 to 30 September 1998 and the planned activities for the next period, 1 October 1998 to 31 December 1998. The activities to be reported here include a theoretical analysis of the airflow in the center air tube in the miniature Triple-Concentric atomizer (TCA) and phase/Doppler particle size and velocity measurements of water and an aqueous polymer solution.

\section{Compressible Airflow Analysis}

Spray visualization results of the spray cone from the miniature TCA, operated in "inverse" twin-fluid mode (a circular air jet surrounded by an annular liquid jet - the outer annular air jet is not operated) showed variations in spray cone angle with flow rate. These results do not appear to support the hypothesis that the center air jet is an underexpanded sonic jet. An underexpanded sonic jet is desirable since the expansion of the jet would cause the water flow to be held against the outer wall of the annular water passage. The acceleration of the water due to shear between the water and air would extrude the liquid, thinning the annulus and reducing the average droplet size.

Minimum flow rate and supply pressure conditions for sonic exit flow must be established. Obviously, the airflow analysis must account for compressibility if the exit flow is sonic. Due to the short lengths of tubing and high velocities, the analysis will assume that there is no heat transfer between the surroundings and the air (adiabatic flow). Friction 
losses in the tubing must be accounted for as well. Adiabatic duct flow with friction uses Fanno line analysis.

\section{Phase/Doppler Measurements}

Droplet size and velocity measurements were made, using a two-component Aerometrics Phase/Doppler Particle Analyzer. Two sets of measurements were made of the spray from the TCA (again operated with the outer airflow turned off, as an "inverse" twinfluid atomizer). The first measurements were made in a spray of water, the second in a spray of a polymer solution. The polymer solution is a $0.05 \%$ solution of polyacrylimide ("E10") in water.

\section{Results and Discussion}

\section{Fanno Line Airflow Analysis}

The analysis of adiabatic compressible flow in a constant-area duct with friction is well known [Benedict, White]. An adiabatic flow with friction will always accelerate (if subsonic) of decelerate (if supersonic) towards a Mach number of one. Computing the losses due to the area change is somewhat more problematic. Work on ultrasonic gas nozzles for liquid metal atomization has addressed this issue before [Ünal, Benedict]. The stagnation pressure loss in compressible flow through an abrupt area change is essentially the same as that observed in incompressible flow.

The analysis is begun by assuming the desired exit conditions: namely, an absolute exit pressure of one atmosphere and an exit Mach number of unity. A schematic diagram of the system is given in Fig. 1, along with the dimensions and exit conditions. The problem is worked upstream from the exit towards the inlet.

A useful property of Fanno line flow is that, being adiabatic, the stagnation temperature does not change. By making the reasonable assumption that the stagnation temperature of the flow is equal to room temperature (since the temperature in the supply reservoir, where velocity is zero, is near room temperature), taken to be $22^{\circ} \mathrm{C}(295 \mathrm{~K})$, the mass flow rate can be computed. The compressible flow table shows that the ratio of temperature to stagnation temperature at sonic conditions, $M=1$, is

$$
\begin{gathered}
{\frac{T}{T_{\circ} M=1}}_{T_{3}}=0.8333 \\
0.8333 T_{\circ}=245.9 \mathrm{~K}
\end{gathered}
$$

Using the ideal gas law yields the local density at the nozzle exit.

$$
\begin{gathered}
p=\rho R T \\
\rho=\frac{p}{R T} \\
\rho=\frac{\left(101.3 \times 10^{3} \mathrm{~N} / \mathrm{m}^{2}\right)}{(287 \mathrm{~J} / \mathrm{kg} \cdot \mathrm{K})(246 \mathrm{~K})}=1.435 \mathrm{~kg} / \mathrm{m}^{3}
\end{gathered}
$$


The sonic velocity depends on the temperature at the exit.

$$
\begin{aligned}
& c=\sqrt{\gamma R T} \\
& V_{3}=c_{3}=\sqrt{(1.4)(287 \mathrm{~J} / \mathrm{kg} \cdot \mathrm{K})(246 \mathrm{~K})}=314.4 \mathrm{~m} / \mathrm{s}
\end{aligned}
$$

The mass flux, with density and velocity (equal to the sonic velocity) known, the mass flux is simply

$$
\begin{gathered}
\dot{m}=\rho A V=\rho \pi D_{3}^{2} / 4 V_{3} \\
\dot{m}=\left(1.435 \mathrm{~kg} / \mathrm{m}^{3}\right) \frac{\pi\left(0.965 \times 10^{-3} \mathrm{~m}\right)^{2}}{4}(314.4 \mathrm{~m} / \mathrm{s})=3.30 \times 10^{-4} \mathrm{~kg} / \mathrm{s}
\end{gathered}
$$

To compute the pressure loss in between points $2 \mathrm{~d}$ and 3 , the property of Fanno-line flow that

$$
\bar{f} \frac{L^{*}}{D}, \frac{p}{p^{*}}, \frac{p_{\circ}}{p_{\circ}^{*}}=f n(M),
$$

where $\bar{f}$ is the average Moody friction factor, $L^{*}$ is the length required for a flow of the local Mach number to reach a Mach number of unity, $D$ is the duct diameter (the first parameter above, $\bar{f} L^{*} / D$, will be designated the Fanno parameter), $p$ is the local static (absolute) pressure, $p^{*}$, is the pressure at the sonic point (corresponding to $L^{*}$ ), $p_{o}$ and $p_{o}{ }^{*}$ are the local and sonic stagnation pressures, respectively (stagnation pressure is not constant due to the non-isentropic nature of the flow).

Between points $2 \mathrm{~d}$ and 3 , the actual values of the friction factor, length, and diameter are known. Therefore, the Mach number at point $2 \mathrm{~d}$ corresponds to the Fanno parameter calculated from the actual values. First, the friction factor must be estimated. Taking a typical roughness for drawn metal tubing of the type used in constructing the TCA, we get a roughness, $\varepsilon=0.001524 \mathrm{~mm}$. The relative roughness is thus

$$
\frac{\varepsilon}{D}=\frac{0.001524 \mathrm{~mm}}{0.965 \mathrm{~mm}}=0.0016
$$

Given that the velocity in the small tube must be in the hundreds of meters per second, it is reasonable to assume that the Reynolds number will be in the fully turbulent region of the Moody chart, where $f$ no longer depends on $R e$.

$$
f \approx 0.023
$$

The Fanno parameter at point $2 \mathrm{~d}$ is then

$$
f \frac{L_{2-3}}{D_{3}}=1.664
$$

Using a table of values of the various ratios for Fanno-line flow [White], the Mach number at any point can be found by determining the Mach number corresponding to the 
value of the Fanno parameter, which can itself be determined by the difference between the tabulated values at known points.

$$
\begin{gathered}
f \frac{\Delta L}{D}=\left(\bar{f} \frac{L^{*}}{D}\right)_{M_{2 d}}-\left(\bar{f} \frac{L^{*}}{D}\right)_{M_{3}} \\
\left(\bar{f} \frac{L^{*}}{D}\right)_{M_{2 d}}=f \frac{L_{2-3}}{D_{3}}+0=1.664 \\
M_{2 d}=M_{\left(\bar{f} \frac{L^{*}}{D}\right)=1.664}=0.443
\end{gathered}
$$

Determining the pressure at point $2 \mathrm{~d}$ is simply a matter of equating the ratios of the pressures to the ratios of the pressure-to-sonic-pressure values from the Fanno-line table. The stagnation pressure is computed using normal isentropic compressible flow tables [White] at the point in question, although $p_{o}$ will vary along the length of the tube due to frictional losses.

$$
\begin{gathered}
\frac{p_{2 d}}{p_{3}}=\frac{\left(p / p^{*}\right)_{M_{2 d}}}{\left(p / p^{*}\right)_{M_{3}=1}}=2.426 \\
p_{2 d}=2.426 p_{3}=245.8 \mathrm{kPa} \\
p_{\circ 2 d}=p_{2 d}\left(p / p_{\circ}\right)_{M_{2 d}}^{-1}=(0.8739)^{-1} p_{2 d}=281.3 \mathrm{kPa}
\end{gathered}
$$

The stagnation pressure loss through the contraction at point 2 is determined by the minor loss coefficient, $k$, for the given geometry. For an abrupt contraction with a diameter ratio of

$$
\frac{d}{D}=\frac{D_{3}}{D_{1}}=0.244
$$

the value of the loss coefficient, $k$, is given (for $d / D<0.75$ ) by [White]

$$
k=0.42\left(1-\left(\frac{d}{D}\right)^{2}\right)=0.395
$$

The stagnation pressure drop through the contraction is given by [Benedict]

$$
\begin{aligned}
& \frac{p_{\circ u}}{p_{\circ d}}=1+\left(1-\frac{\gamma-1}{2} M_{d}^{2}\right) k \\
& p_{\circ 2 u}=1.05 p_{\circ 2 d}=295.3 \mathrm{kPa}
\end{aligned}
$$

The pressure and Mach number upstream of the contraction are found by equating the mass flow up- and downstream of the contraction. 


$$
\begin{gathered}
\dot{m}=\frac{p_{\circ}}{\left(R T_{\circ}\right)^{1 / 2}} A \gamma^{1 / 2}\left(\frac{2 \gamma}{\gamma+1}\right)^{(\gamma+1) / 2(\gamma-1)}\left(\frac{A}{A^{*}}\right)^{-1} \\
\dot{m}_{2 d}=\dot{m}_{2 u} \\
\left(\frac{A}{A^{*}}\right)_{M_{2 u}} A_{2 d}\left(\frac{A}{A^{*}}\right)_{M_{2 d}}^{-1}=p_{\circ 2 u} A_{2 u}\left(\frac{A}{A^{*} 2 u}\right)_{M_{2 u}}^{-1} \frac{D_{3}^{2}}{D_{1}^{2}}\left(\frac{A}{A^{*}}\right)_{M_{2 d}}=(1.05)(0.244)^{2}(1.467) \\
\left(\frac{A}{A^{*}}\right)_{M_{2 u}}=25.95
\end{gathered}
$$

This value is too large (yielding a Mach number too close to zero) for interpolation to be reliable. The asymptotic limit of the behavior of Fanno line flow gives a Mach number based on the area ratio of

$$
\begin{gathered}
M \approx \frac{1+0.27\left(A / A^{*}\right)^{-2}}{1.728\left(A / A^{*}\right)} \quad \text { for } M<1,1.34<A / A^{*}<\infty \\
M_{2 u}=0.0223
\end{gathered}
$$

The Mach number upstream of the contraction is so low that the compressibility of air can be safely neglected. The pressure loss in the larger supply tube (from point 1 to $2 \mathrm{u}$ ) can be determined with simpler incompressible analyses [White]. In addition to a constant stagnation temperature, an incompressible flow generally has a constant temperature, taken here to be room temperature $\left(22^{\circ} \mathrm{C}\right.$, or $\left.295 \mathrm{~K}\right)$. The pressure loss is dependent on the friction factor, the tube geometry and the flowrate.

$$
? p=p_{2 u}-p_{1}=f \frac{L}{D}\left(\frac{1}{2} \rho V^{2}\right)
$$

Since the temperature is known, and the pressure at point $2 u$ is known, the density can be computed. With density, velocity and Reynolds number may be determined.

$$
\begin{gathered}
\rho_{1}=\frac{p_{2 u}}{R T_{\circ}}=\frac{\left(295.3 \times 10^{3} \mathrm{~N} / \mathrm{m}^{2}\right)}{(287 \mathrm{~J} / \mathrm{kg} \cdot \mathrm{K})(295 \mathrm{~K})}=3.488^{\mathrm{kg}} / \mathrm{m}^{3} \\
V_{1}=\frac{\dot{m}}{\rho A_{1}}=\frac{\left(3.3 \times 10^{-4} \mathrm{~kg} / \mathrm{s}\right)}{\left(3.488^{\mathrm{kg} / \mathrm{s}}\right)\left(1.233 \times 10^{-5} \mathrm{~m}^{2}\right)}=7.68 \mathrm{~m} / \mathrm{s} \\
\operatorname{Re}=\frac{\rho V D}{\mu}=\frac{\left(3.488^{\mathrm{kg} / \mathrm{m}^{3}}\right)(7.68 \mathrm{~m} / \mathrm{s})\left(3.962 \times 10^{-3} \mathrm{~m}\right)}{\left(1.8 \times 10^{-5} \mathrm{~N} \cdot \mathrm{s} / \mathrm{m}^{2}\right)}=5900 \\
\frac{\varepsilon}{D}=\frac{\left(1.52 \times 10^{-3} \mathrm{~mm}\right)}{(3.962 \mathrm{~mm})}=0.00038 \\
f(\operatorname{Re} \approx 6000, \varepsilon / D \approx 0.0004)=0.0355
\end{gathered}
$$


So the pressure loss and upstream pressure, $p_{l}$, are

$$
\begin{gathered}
? p=f \frac{L}{D}\left(\frac{1}{2} \rho V^{2}\right)=(0.0355) \frac{(178 \mathrm{~mm})}{(3.962 \mathrm{~mm})}\left(\frac{1}{2}\left(3.488 \mathrm{~kg} / \mathrm{m}^{3}\right)(7.68 \mathrm{~m} / \mathrm{s})^{2}\right)=0.164 \mathrm{kPa} \\
p_{1}\left(\approx p_{\circ 1}\right)=p_{2 u}+? p=295.5 \mathrm{kPa}(\text { absolute })
\end{gathered}
$$

A standard rotameter was used to measure the air flow rate. The scale reads in L/min at STP. A correction is necessary if the pressure at the flow meter is not atmospheric. The indicated flow rate should read:

$$
\begin{gathered}
Q_{a c t}=Q_{\text {ind }} \sqrt{\frac{p}{p_{a t m}}} \\
Q_{\text {ind }}=Q_{a c t}\left(\frac{p}{p_{a t m}}\right)^{-1 / 2}=(16 L / \mathrm{min})\left(\frac{295.5 \mathrm{kPa}}{101.3 \mathrm{kPa}}\right)^{-1 / 2}=9.4 \mathrm{~L} / \mathrm{min}
\end{gathered}
$$

\section{Phase/Doppler Droplet Size Measurements}

Using the larger of the two triple-concentric atomizers (constructed during the fourth quarter of 1997, see Fig. 2), comparative measurements of droplet size were made of sprays of water and a dilute polymer solution. The polymer solution consisted of $0.05 \%$ by weight high-molecular weight polyacrylimide dissolved in distilled water. The spray conditions (air flow rates and supply pressures and liquid flow rates) were identical in the two experiments.

The measurements were made with an Aerometrics two-component Phase/Doppler Particle Analyzer. The spray was oriented perpendicular to the PDPA transmitter axis, but at a $45^{\circ}$ angle to the vertical. The measurement locations and velocity measurements were transformed to utilize a coordinate system fixed to the atomizer, where $r$ is radial distance from the spray axis and $z$ is axial distance from the atomizer exit.

The two velocity components measured by the PDPA were transformed to yield an axial velocity. The velocity measurements show no noticeable difference in drop velocity between the water and polymer solution sprays. This is unsurprising since the aerodynamic forces drive the drop acceleration and the aerodynamic forces should be identical in both cases.

Two sets of measurements were made, at axial distances of 100 and 150 millimeters from the atomizer exit. The droplet size measurements show a slight increase in drop size when first water and then polymer solution is sprayed (see Fig. 3). Even this relatively small increase in drop size $(\sim 3 \mu \mathrm{m})$ is significant when put in the perspective that an approximately $9 \%$ increase in drop size was caused by the addition of $0.05 \%$ (by weight) of polymer.

\section{Conclusion}

In order to realize the full potential of the triple-concentric atomizer, sonic exit conditions must exist for the center air flow. Great care must be taken to ensure that that these conditions exist. Compressible airflow analysis shows that a very large pressure drop 
occurs across the last, smallest diameter, section of the metal tubing. In the case of the miniature TCA, the pressure drop along the last $70 \mathrm{~mm}$ of tubing is 600 times larger than the pressure drop through the abrupt contraction and $200 \mathrm{~mm}$ of tubing leading from the flowmeter to the contraction at the atomizer connection. For the miniature TCA, the analysis shows that a minimum flow rate of $20 \mathrm{~g} / \mathrm{min}$ (or $16 \mathrm{~L} / \mathrm{min}$ at $\mathrm{STP}$ ) is required; the necessary supply stagnation pressure is $296 \mathrm{kPa}$ (absolute).

Measurements of the droplet sizes in water and polymer solution sprays generated by the standard TCA show a nearly $10 \%$ increase in the Sauter mean drop diameter from the addition of $0.05 \%$ by weight of polymer material to distilled water. The effect of this much solute on the solution properties such as shear viscosity and surface tension is on the order of 1-2\%. This evidence supports the conclusion that the extensional viscosity (which has been shown to be extremely sensitive to polymer solute concentration at very low concentrations) affects the formation of droplets in an air-assisted spray.

\section{Projected Activity for Next Period}

During the next quarter, extensional viscosity measurements and drop size

measurements will be made to determine the relative sensitivity of drop size to various polymer solutes.

\section{References}

Benedict, R. P., Fundamentals of Pipe Flow, Wiley Interscience, New York, 1980, pp. 292-343, 363-420

Ünal, A., "Frictional losses in ultrasonic gas atomisation nozzles", Powder Metallurgy, v. 33, n. 4, 1990, pp. 327-333

White, F. M., Fluid Mechanics, $3^{\text {rd }}$ ed., McGraw-Hill, New York, 1994, pp.307-318, 335340, 704-711 


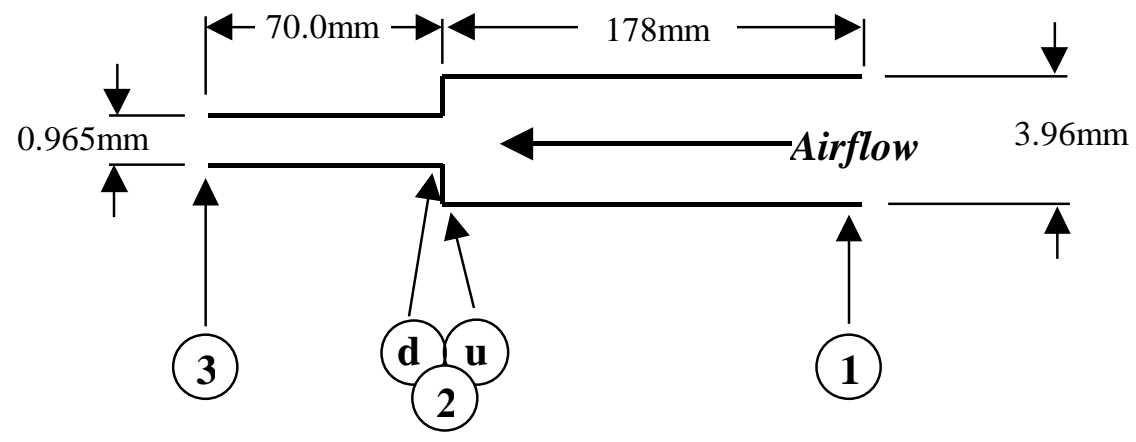

Figure 1: Center Air Passages, Miniature Triple-Concentric Atomizer

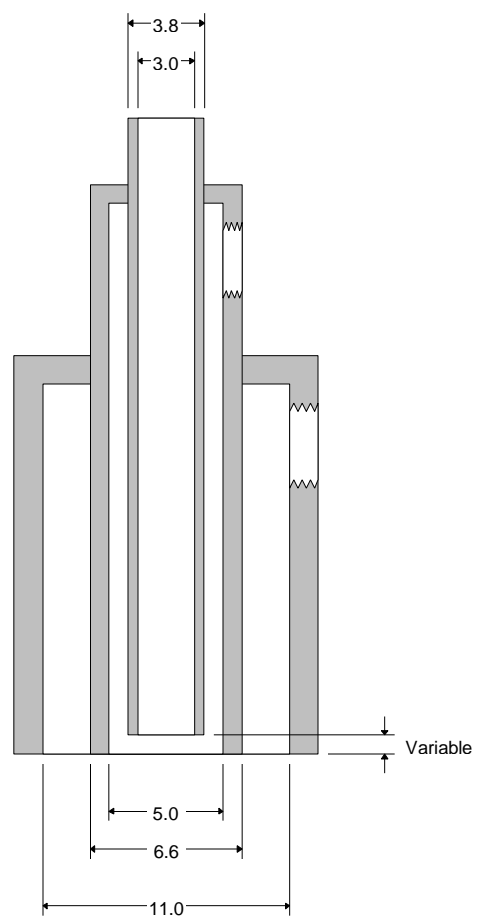

Figure 2: Schematic Diagram, Triple-Concentric Atomizer 


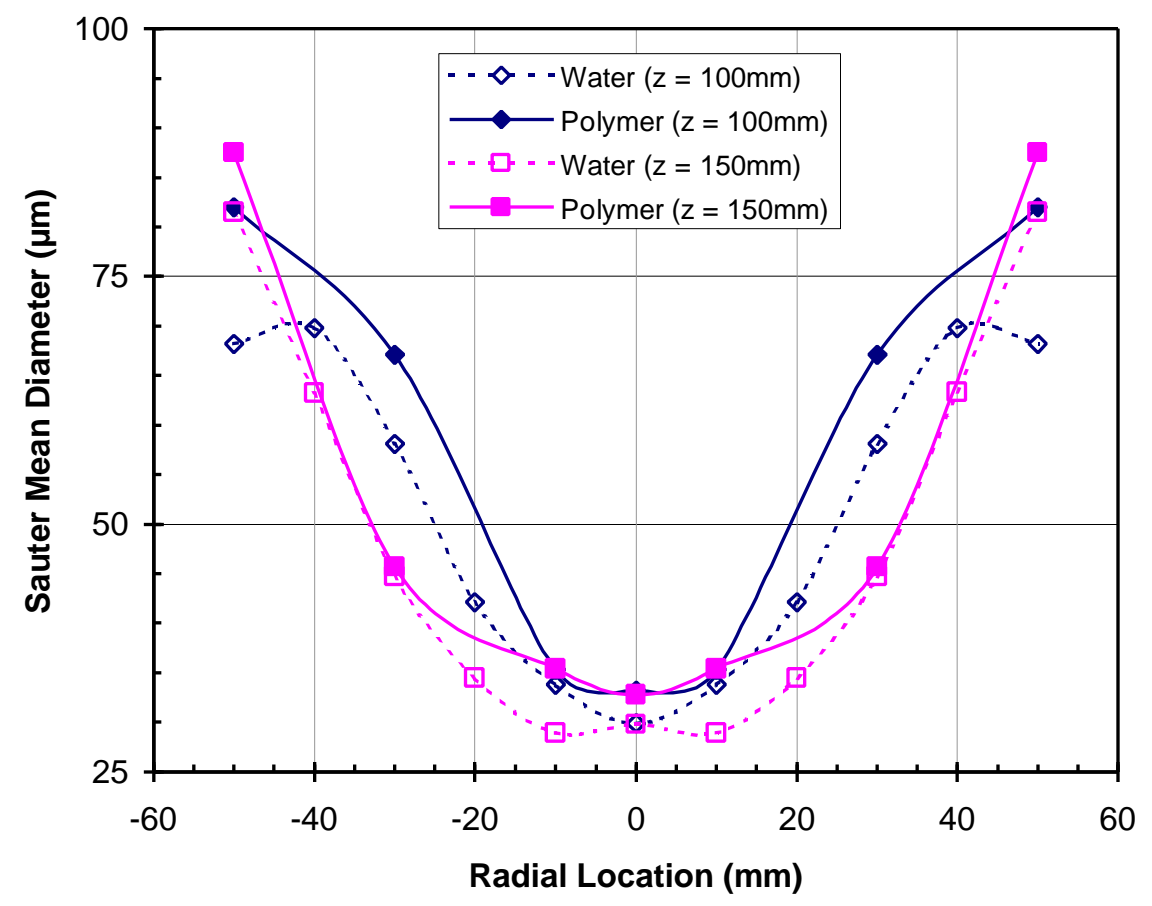

Figure 3: Drop Sizes, Water spray vs. Polymer solution spray 